that the molecules in a liquid rotate freely, unhindered by their neighbours. The structure is quasicrystalline with regard to orientation as well as to translation.

In the concluding reports Kast dealt with anisotropic liquids, Jenckel with glasses and Wittstadt with rubber. The transformation of such a liquid as $p$-azoxyanisole to the nematic state, at which we know from the optical properties that some 30 per cent of the rod-shaped molecules suddenly become roughly parallel to one another over fairly wide regions while the $\mathrm{X}$-ray scattering diagram scarcely alters and the fluidity actually increases, is probably one of the simplest of all transitions of a quasicrystalline to a crystalline state. Kast's presentation of the facts was very favourable to Frank's theoretical description of the change. Jenckel concerned himself mainly with the transformation point of glasses. This is the temperature at which the viscosity becomes so high (about $10^{13}$ ) that molecular rearrangement no longer takes place in times compatible with human patience. Below this temperature the coefficient of expansion and the specific heat are much smaller. It is chiefly interesting in the present connexion for showing that molecular rearrangement in the liquid contributes largely to these properties above that temperature. Rubber provides a superb example of the way in which the various lines of attack described above, thermal, Röntgenographic, dielectric and statistical mechanical, have been applied to the elucidation of a peculiarly complex case. The presence together of Kuhn, Meyer and Thiessen ensured a lively discussion.

Prof. Wagner and the Bunsen-Gesellschaft are to be congratulated on the success of this, the second Diskussionstagung which it has organized after the Faraday Society model, circulating all main contributions in full beforehand.

F. C. Frank,

\title{
Science and the Army
}

$\mathrm{A}^{\mathrm{T}}$ T the Science Museum, South Kensington, there has been arranged a special War Office Exhibition which, for a period of three months, gives visitors an opportunity of acquainting themselves with the numerous points at which science comes into contact with the work of the British Army. It will probably surprise many to learn that, at the several training centres for boys who enter at fourteen years of age, technical instruction, both practical and theoretical, is given which compares favourably with that obtained by the average apprentice in civil life. At the Military College of Seience, Woolwich, this reaches its highest development in the training for the grade of artificer, Royal Artillery, the course for which extends over five years and produces men of high technical skill. Mechanization accounts for a great increase in the engineering requirements of Army services, and the extent of this will be realized from the exhibits showing the preparations for the driving and maintenance of transport vehicles and tanks and for the repairs carried out in the heavy workshops operated by the Royal Engineers and Royal Army Service Corps. The high stage of development reached in the signals and wireless services is demonstrated and here, to a large extent, the apparatus has to be specially designed for the conditions of use in the field, though, so far as possible, commercial forms are adopted.

In certain branches, it will be seen that the Army has been leading the way, and this is notably the case in the making of maps. The exhibit shows that the War Office, breaking away from the Continental practice, has developed a comparatively simple method of aerial surveying, and the various stages of making the types of maps which can be produced in the field are illustrated. The manifold services of the Royal Engineers can be seen in exhibits of different kinds of bridges made and used in war, and in examples of demolitions, water supply arrangements with well-sinking and distribution, and such work as the drainage schemes carried out in conjunction with Royal Army Medical Corps anti- malarial measures at places like Singapore. Medical science is represented by models of field disinfectors, water purifiers and the latest type of small cooker for use in tanks.

In the Air Defence Section some highly scientific exhibits are to be seen. The sound locator is based on the principle of human hearing whereby, when waves of sound reach the ear, the head is turned until they come equally to each ear. So, the locator is turned until its trumpets, one pair for bearing and one pair for elevation, give the position of the source of the sound. The Vickers predictor is, in a like sense, a pair of mechanical eyes. In addition to ranging its target, it gives the bearing, the elevation, and the right fuse-setting, making allowance for trajectory curve, wind, and even for variation in barometric pressure in the upper air. Its information is transmitted electrically to dials on the guns, and all that the men on the gun have to do is to keep mechanical pointers in line with the electrical pointers.

Research in Army matters is much more coordinated than it is in civil affairs. Development in one direction has immediate repercussions in others -if, for example, a gun of higher rate of fire is visualized, questions as to ammunition, supplies, and possibly man-power will have to be dealt withand consequently the research organization is very broadly based as the exhibition will show. A most interesting exhibit is the R. D. Camera which films shells as they are actually fired. The Ballistic Section also shows the Brown-Hall photographic lorry which enables this filming to be done in the field and the cascade thyratron which measures bullet velocities when 'bursts' are fired. The Chemical Research Branch at Porton and the Experimental Establishment at Biggin Hill are also represented, and this section of the Exhibition conveys an impression of the unceasing scientific inquiry that is conducted by the War Office to ensure that the highest efficiency of man and material may be attained in the requirements of the Service. 